
\title{
25 Research Soure \\ Plasma Fibrinogen, D-dimer, and Fibrin Degradation Product as Biomarkers of Rheumatoid Arthritis
}

\section{Li Xue}

Department of Clinical Laboratory, The Second Affiliated Hospital of Xi'an Jiaotong University https://orcid.org/0000-0001-8580-6609

\section{Ming Li}

Xi'an Jiaotong University

\section{Li Tao}

Xi'an Jiaotong University

\section{Xueyi Li}

Xi'an Jiaotong University

\section{Wei Wang}

Xi'an Jiaotong University

\section{Yan Wang}

Xi'an Jiaotong University

\section{Biao Wang}

Xi'an Jiaotong University

\section{Yanping Zhang}

Xi'an Jiaotong University

\section{Ning Gao}

Xi'an Jiaotong University

\section{Yanying Dong}

Xi'an Jiaotong University

\section{Ting Zhou}

Xi'an Jiaotong University

\section{Zeshi Liu}

Xi'an Jiaotong University

Hailong Liu

Xi'an Jiaotong University

Juntao He

Xi'an Jiaotong University

Ke Li

Xi'an Jiaotong University

Yan Geng ( $\sim$ gengyanjyk@126.com ) 
Research article

Keywords: rheumatoid arthritis, plasma, spearman correlation, fibrinogen

Posted Date: July 29th, 2020

DOI: https://doi.org/10.21203/rs.3.rs-49004/v1

License: (c) (i) This work is licensed under a Creative Commons Attribution 4.0 International License. Read Full License 


\section{Abstract}

Objective: This study aimed to assess the role of coagulation-related indicators such as plasma fibrinogen (FIB), D-dimer, and fibrin degradation product (FDP) in rheumatoid arthritis (RA) and their association with disease activity.

Methods: Data from 105 RA patients and 102 age- and gender- matched healthy controls were collected in the retrospective study. Disease activity score in 28 joints based on C-reactive protein (DAS28-CRP) was used to divide the RA patients into inactive group (DAS28-CRP $\leq 2.7$ ) and active group (DAS28-CRP $>2.7$ ). The association between plasma FIB, D-dimer, and FDP and DAS28-CRP was evaluated by spearman correlation. Receiver operating characteristic (ROC) curve was applied to determine the area under curve (AUC) value. The prognostic value of plasma FIB, D-dimer, and FDP in the RA disease activity was tested by logistical regression analysis.

Results: RA patients showed higher FAR levels of plasma FIB, D-dimer, and FDP than the controls $(P<$ 0.01). Plasma FIB, D-dimer, and FDP were also increased in active group of RA patients than those in inactive group $(P<0.001)$. Spearman analysis showed that plasma FIB, D-dimer, and FDP were positively related with DAS28-CRP $(P<0.001)$ in RA patients. ROC curve analyses revealed that the AUC of D-dimer was higher than ESR and RF, and that of FDP was higher than RF in RA patients. In addition, the optimal cut-off value of plasma FIB, D-dimer, and FDP for RA diagnosis was $286 \mathrm{mg} / \mathrm{dL}, 470 \mu \mathrm{g} / \mathrm{L}$, and 1.45 $\mathrm{mg} / \mathrm{L}$, respectively. Logistical regression analyses showed that D-dimer (odds ratio $=2.862,95 \%$ confidence interval: 1.851-4.426, $P<0.001)$ was a predictor for RA disease activity.

Conclusions: FIB, D-dimer, and FDP were increased in RA patients and positively correlated with the disease activity of RA. D-dimer may act as a novel inflammatory parameter for predicting disease activity in RA patients.

\section{Introduction}

Rheumatoid arthritis (RA) is a systemic inflammatory autoimmune disease characterized by inflammation and proliferation of synovium, progressive destruction of articular cartilage and bone, which eventually lead to severe disability, systemic complications and increased risk of mortality [1, 2]. The estimated prevalence of RA is approximately $0.5-1 \%$ in adults and is continually growing worldwide [3]. With accumulating effective biologics applied to RA, early diagnosis and accurate assessment of disease activity are absolutely urgent [4]. However, present laboratory parameters, including erythrocyte sedimentation rate (ESR), C-reactive protein (CRP), rheumatoid factor (RF), and anti-cyclic citrullinated peptide (CCP) are not reliable for early diagnosis and monitoring of therapeutic effect.

Recently it is regarded that immune and coagulation systems are functionally connected $[5,6]$. Proinflammatory cytokines and other mediators have been described to be responsible for activating the coagulation system as well as down-regulating important physiologic anticoagulant pathways [7-10]. A previous study revealed that IL- 6 could mediate thrombocytosis, platelet hyperreactivity, and accelerate 
extra-intestinal thrombosis associated with experimental colitis [11]. Another study showed that IL-6 and T-cell-dependent IL-6 signaling was involved in angiotensin II-induced thromboinflammation [12]. As one of the most important members in the coagulation system, tissue factor could also mediate the production of pro-inflammatory cytokines by activating protease-activated receptors on various cells such as mononuclear cells, endothelial cells, platelets, and so on [13]. Based on these findings, several studies indicated the important role of coagulation-related indices in assessing the disease activity of autoimmune diseases [14].

It has been reported that autoimmune diseases such as RA, ankylosing spondylitis, and lupus nephritis are associated with disorders of coagulation system [15-17]. There are studies showing that coagulation is activated in the joint of RA patients $[15,18]$, and alterations in levels of coagulation factors have been related to vascular disease in RA [19]. Fibrinogen (FIB) is a key factor implicated in the process of blood coagulation cascade, and its deposition in the joint was recognized to be characteristic of RA and even may be responsible for the formation of pannus tissue [15]. However, little is known about the predictive role of peripheral blood FIB in RA patients. D-dimer is a fibrin degradation product (FDP) and is the most frequently used indicator to reflect the activation of the coagulation system. D-dimer and other FDPs could also affect inflammatory responses by promoting the activation of monocyte, leading to the release of inflammatory cytokines such as IL-6 [20, 21]. Although the level of D-dimer was reported to be increased in the synovial fluid of RA patients compared with osteoarthritis patients [15], there were few reports concerning the association between the level of D-dimer in peripheral blood and the disease activity of RA patients. The aim of this study was to investigate the diagnostic role of coagulation-related indicators including plasma FIB, D-dimer, and FDP in patients with RA. The correlation of these indicators with disease activity in RA was also evaluated.

\section{Method}

\section{Study population}

This study included 105 RA patients who were admitted to the Department of Rheumatology and Immunology of the Second Affiliated Hospital of Xi'an Jiaotong University during the period from October 2017 to February 2020. All the patients fulfilled the 2010 American College of Rheumatology criteria for RA [22]. Patients who had other autoimmune inflammatory diseases, hematologic diseases, malignancies, infections, or had any history of other chronic diseases such as diabetes mellitus, dyslipidemia, thyroid dysfunction, severe liver or kidney impairment as well as those receiving corticosteroids treatment within the last 3 months were excluded. 102 healthy subjects were recruited from the health examination center of our hospital, and matched with RA patients for age and gender. The study was approved by the Research Committee of Human Investigation of Xi'an Jiaotong University Health Science Center and all subjects gave written informed consent.

\section{Assessment of disease activity}


Using the Disease Activity Score in 28 joints based on C-reactive protein (DAS 28-CRP) [23, 24], disease activity of RA patients can be described as low (DAS $28-C R P \leq 2.7)$, moderate $(2.7<$ DAS 28 -CRP $\leq 4.1)$ or high (DAS 28-CRP > 4.1), respectively. We define patients with moderate and high disease activity as active RA, whereas those with low disease activity were defined as inactive RA.

\section{Clinical and laboratory parameters}

Patients' characteristics, including age, gender, medical history, symptoms and signs, diagnosis, treatment, laboratory testing results were collected from their electronic medical records. Blood samples were obtained on the day of admission and sent to our hospital's clinical laboratory for testing plasma FIB, D-dimer, FDP, and other indices.

\section{Statistical analysis}

The normality of data distribution was examined by the Kolmogorov-Smirnov test. Continuous variables with the normal distribution were presented as mean values \pm standard deviation. Non-normally distributed data were presented as median (interquartile range). Categorical variables were described as frequencies or percentages. The differences of continuous variables were compared using The Student's t-test or Mann-Whitney U test, while the chi-square test was performed to compare the differences of categorical variables. Spearman's correlation analysis was applied to examine the association between variables. Receiver operating characteristic (ROC) curves were plotted to distinguish RA patients from healthy individuals and active group of RA patients from inactive group. The area under the curve (AUC) and $95 \%$ confidence interval $(\mathrm{Cl})$ were calculated to evaluate the diagnostic value of each test. The optimal cut-off value, sensitivity, specificity, positive predictive value (PPV), negative predictive value (NPV) and accuracy (AC) of the tests were determined. Binary logistical regression model was used to assess the associated factors of RA disease activity (inactive group VS. active group). After univariate regression analysis, variables with $P<0.10$ were included in the further forward stepwise regression analysis. Statistical significance was considered as a two-tailed $P$ value less than 0.05 . All statistical analysis was conducted using SPSS software (version 16.0, Chicago, IL, USA).

\section{Results}

\section{Study population}

Clinical and laboratory characteristics of RA patients and healthy controls were shown in Table 1 . There were no differences in age and gender distribution, body mass index (BMI), white blood cells (WBC) and platelet (PLT) between the two groups. Besides, red blood cells (RBC) and hemoglobin (Hb) in RA patients were significantly lower than that in the control group $(P<0.001)$. Table 2 showed clinical and laboratory characteristics of RA patients. Age, gender, BMI, disease duration, WBC, RBC, PLT and CCP were similar between the active RA and inactive RA groups. The active RA patients had higher levels of ESR, CRP and RF compared with inactive RA groups $(P<0.001$ or $P<0.05)$. But active RA patients presented reduced $\mathrm{Hb}$ levels relative to inactive RA groups. 
Table 1

\begin{tabular}{|c|c|c|c|}
\hline & RA & Control & $P$-value \\
\hline Age (years) & $55.26 \pm 16.27$ & $53.69 \pm 14.95$ & 0.117 \\
\hline Gender (F/M) & $78 / 27$ & $76 / 26$ & 0.971 \\
\hline $\operatorname{BMI}\left(\mathrm{kg} / \mathrm{m}^{2}\right)$ & $25.2 \pm 2.7$ & $25.8 \pm 3.2$ & 0.20 \\
\hline CRP (mg/L) & 19.48(7.21-50.62) & $1.9(0.7-2.9)$ & $<0.001$ \\
\hline $\mathrm{ESR}(\mathrm{mm} / \mathrm{h})$ & $43.0(17-76)$ & $5.61(2.93-10.45)$ & $<0.001$ \\
\hline $\mathrm{RF}(\mathrm{IU} / \mathrm{mL})$ & $171.56(25.2-410.00)$ & $5.02(2.30-13.40)$ & $<0.001$ \\
\hline $\mathrm{CCP}(\mathrm{U} / \mathrm{mL})$ & $273.6(43.8-395.0)$ & $11.1(6.2-17.5)$ & $<0.001$ \\
\hline WBC $\left(10^{9} / \mathrm{L}\right)$ & $6.65 \pm 3.02$ & $6.09 \pm 2.23$ & 0.139 \\
\hline $\operatorname{RBC}\left(10^{12} / \mathrm{L}\right)$ & $4.09 \pm 0.64$ & $4.64 \pm 0.62$ & $<0.001$ \\
\hline $\mathrm{Hb}(\mathrm{g} / \mathrm{L})$ & $118.48 \pm 20.77$ & $137.20 \pm 18.28$ & $<0.001$ \\
\hline $\operatorname{PLT}\left(10^{9} / \mathrm{L}\right)$ & $230.89 \pm 87.93$ & $220.65 \pm 64.33$ & 0.353 \\
\hline $\mathrm{FIB}(\mathrm{mg} / \mathrm{dL})$ & $370.40 \pm 126.02$ & $274.73 \pm 73.39$ & $<0.001$ \\
\hline D-dimer (ug/L) & $2962.78 \pm 1892.94$ & $907.13 \pm 545.65$ & $<0.001$ \\
\hline $\mathrm{FDP}(\mathrm{mg} / \mathrm{L})$ & $19.43 \pm 12.31$ & $2.15 \pm 1.03$ & $<0.01$ \\
\hline \multicolumn{4}{|c|}{ Comparison of clinical characteristics between RA patients and controls. } \\
\hline \multicolumn{4}{|c|}{$\begin{array}{l}\text { F: female; M: male; BMI: body mass index; CRP, C-reactive protein; ESR, erythrocyte sedimentation rate; } \\
\text { RF, rheumatoid factor; CCP, anti-cyclic citrullinated peptide; WBC, white blood cells; RBC, red blood } \\
\text { cells; Hb: hemoglobin; PLT: platelet; FIB: fibrinogen; FDP: fibrin degradation product. }\end{array}$} \\
\hline
\end{tabular}


Table 2

Comparison of clinical characteristics between the two RA subgroups.

\begin{tabular}{|c|c|c|c|}
\hline & $\begin{array}{l}\text { Inactive RA } \\
(N=52)\end{array}$ & $\begin{array}{l}\text { Active RA } \\
(N=53)\end{array}$ & $P$-value \\
\hline Age (years) & $53.28 \pm 19.00$ & $56.98 \pm 13.64$ & 0.236 \\
\hline Gender (F/M) & $39 / 13$ & $39 / 14$ & 0.868 \\
\hline BMI $\left(\mathrm{kg} / \mathrm{m}^{2}\right)$ & $25.5 \pm 3.1$ & $24.7 \pm 2.3$ & 0.45 \\
\hline CRP (mg/L) & $10.95(5.87-16.9)$ & $30.30(10.56-53.90)$ & $<0.001$ \\
\hline $\operatorname{ESR}(\mathrm{mm} / \mathrm{h})$ & $28.0(15-62)$ & $57.0(21-83)$ & $<0.001$ \\
\hline $\mathrm{RF}(\mathrm{IU} / \mathrm{mL})$ & $131.83(21.20-310.00)$ & $275.29(35.16-907.00)$ & $<0.05$ \\
\hline $\mathrm{CCP}(\mathrm{U} / \mathrm{mL})$ & $251.3(20.6-375.0)$ & $306.8(91.7-400.0)$ & 0.373 \\
\hline $\lg G(g / L)$ & $13.52 \pm 3.76$ & $16.91 \pm 5.13$ & $<0.05$ \\
\hline $\lg A(g / L)$ & $2.63 \pm 1.18$ & $3.35 \pm 1.67$ & $<0.05$ \\
\hline $\lg M(g / L)$ & $1.19 \pm 0.63$ & $1.43 \pm 0.74$ & $<0.05$ \\
\hline WBC $\left(10^{9} / \mathrm{L}\right)$ & $6.42 \pm 2.82$ & $6.88 \pm 3.36$ & 0.480 \\
\hline $\operatorname{RBC}\left(10^{12} / \mathrm{L}\right)$ & $4.14 \pm 0.51$ & $4.03 \pm 0.56$ & 0.173 \\
\hline $\mathrm{Hb}(\mathrm{g} / \mathrm{L})$ & $123.12 \pm 20.38$ & $116.37 \pm 17.95$ & $<0.05$ \\
\hline $\operatorname{PLT}\left(10^{9} / \mathrm{L}\right)$ & $216.05 \pm 84.98$ & $239.87 \pm 89.13$ & 0.107 \\
\hline $\mathrm{FIB}(\mathrm{mg} / \mathrm{dL})$ & $315.58 \pm 96.44$ & $401.76 \pm 122.10$ & $<0.001$ \\
\hline D-dimer (ug/L) & $2145.61 \pm 975.12$ & $4382.46 \pm 1881.72$ & $<0.001$ \\
\hline FDP (mg/L) & $5.17 \pm 3.48$ & $37.13 \pm 13.44$ & $<0.001$ \\
\hline \multicolumn{4}{|c|}{$\begin{array}{l}\text { Patients in inactive group with a DAS 28-CRP score lower than } 2.7 \text {; active patients with a DAS 28-CRP } \\
\text { score of } 2.7 \text { and higher. DAS28-CRP, Disease Activity Score in } 28 \text { joints based on C-reactive protein; F, } \\
\text { female; M, male; BMI: body mass index; CRP, C-reactive protein; ESR, erythrocyte sedimentation rate; } \\
\text { RF, rheumatoid factor; CCP, anti-cyclic citrullinated peptide; Ig G: immunoglobulin G; Ig A: } \\
\text { immunoglobulin A; Ig M: immunoglobulin M; WBC, white blood cells; RBC, red blood cells; Hb: } \\
\text { hemoglobin; PLT: platelet; FIB: fibrinogen; FDP: fibrin degradation product. }\end{array}$} \\
\hline
\end{tabular}


Table 3

\begin{tabular}{|c|c|c|c|c|c|c|}
\hline \multirow[t]{2}{*}{ Parameters } & \multicolumn{2}{|l|}{$\begin{array}{l}\text { CRP } \\
\text { (mgL) }\end{array}$} & \multicolumn{2}{|c|}{$\begin{array}{l}\text { ESR } \\
(\mathrm{mm} / \mathrm{h})\end{array}$} & \multicolumn{2}{|c|}{ DAS28-CRP } \\
\hline & $\mathbf{r}$ & $P$-value & $\mathbf{r}$ & $P$-value & $\mathbf{r}$ & $P$-value \\
\hline $\mathrm{FIB}(\mathrm{mg} / \mathrm{dL})$ & 0.557 & $<0.001$ & 0.502 & 0.001 & 0.422 & $<0.001$ \\
\hline D-dimer( $\mu \mathrm{g} / \mathrm{L})$ & 0.647 & $<0.001$ & 0.619 & $<0.001$ & 0.490 & $<0.001$ \\
\hline $\mathrm{FDP}(\mathrm{mg} / \mathrm{L})$ & 0.611 & $<0.001$ & 0.568 & $<0.001$ & 0.491 & $<0.001$ \\
\hline
\end{tabular}

Correlations of FIB, D-dimer and FDP with disease activity indices in RA patients.

CRP, C-reactive protein; ESR, erythrocyte sedimentation rate; DAS28-CRP, Disease Activity Score in 28 joints based on C-reactive protein; FIB: fibrinogen; FDP: fibrin degradation product.

\section{Plasma levels of FIB, D-dimer and FDP}

As shown in Table 1, plasma levels of FIB, D-dimer and FDP were increased compared with that of healthy controls $(P<0.001$ or $P<0.01)$. Patients with active RA showed higher levels of plasma fibrin, $D-$ dimer and FDP in comparison to inactive RA group (Table $2, \mathrm{P}<0.001$ ).

In order to evaluate the diagnostic performance of plasma fibrin, D-dimer and FDP, we further used ROC curve analysis. As shown in Fig. 1 and Table 4, the AUC of FIB, D-dimer and FDP was $0.782,0.777$ and 0.762 respectively (all $P<0.001$ ) for RA patients versus healthy controls. No significant difference in the AUC of three markers for distinguishing between RA patients and healthy control $(P>0.05)$.

Table 4

The diagnostic value of FIB, D-dimer and FDP for RA.

\begin{tabular}{|c|c|c|c|c|c|c|c|c|}
\hline Parameters & AUC & $95 \% \mathrm{Cl}$ & $\begin{array}{l}\text { Optimal } \\
\text { cut-off } \\
\text { value }\end{array}$ & $\begin{array}{l}\text { Specificity } \\
(\%)\end{array}$ & $\begin{array}{l}\text { Sensitivity } \\
(\%)\end{array}$ & $\begin{array}{l}\text { PPV } \\
\text { (\%) }\end{array}$ & $\begin{array}{l}\text { NPV } \\
\text { (\%) }\end{array}$ & $\begin{array}{l}A C \\
(\%)\end{array}$ \\
\hline $\begin{array}{l}\text { FIB } \\
(\mathrm{mg} / \mathrm{dL})\end{array}$ & 0.782 & $\begin{array}{l}0.712- \\
0.842\end{array}$ & $>286$ & 75.61 & 78.91 & 76.39 & 78.19 & 77.26 \\
\hline $\begin{array}{l}\text { D-dimer } \\
(\mu \mathrm{g} / \mathrm{L})\end{array}$ & 0.777 & $\begin{array}{l}0.706- \\
0.837\end{array}$ & $>470$ & 77.50 & 68.75 & 75.34 & 77.50 & 73.13 \\
\hline $\begin{array}{l}\mathrm{FDP} \\
\text { (mg/L) }\end{array}$ & 0.762 & $\begin{array}{l}0.691 \text { to } \\
0.825\end{array}$ & $>1.45$ & 77.50 & 71.09 & 75.96 & 72.83 & 74.30 \\
\hline
\end{tabular}


Table 5

showed the ROC curve analysis for the active and inactive group of RA patients. The AUC of D-dimer was $0.755,0.825$ and 0.793 for active RA versus inactive RA (all $P<0.001$ ). The optimal cutoff values of FIB, D-dimer and FDP between active RA and inactive RA groups were $390 \mathrm{mg} / \mathrm{DI}, 1230 \mu \mathrm{g} / \mathrm{L}$, and $1.81 \mathrm{mg} / \mathrm{L}$. As shown in Fig. 2, D-dimer had a higher AUC relative to ESR, RF and CCP in distinguishing between active RA patients and inactive group $(P<0.05, P<0.001$ and $P<0.001$, respectively). FDP had a higher

AUC relative to RF and CCP while FIB had a higher AUC to CCP in distinguishing between active RA patients and inactive group $(P<0.01, P<0.001$ or $P<0.05)$.

\begin{tabular}{|c|c|c|c|c|c|c|c|c|}
\hline Parameters & AUC & $95 \% \mathrm{Cl}$ & $\begin{array}{l}\text { Optimal } \\
\text { cut-off } \\
\text { value }\end{array}$ & $\begin{array}{l}\text { Specificity } \\
\text { (\%) }\end{array}$ & $\begin{array}{l}\text { Sensitivity } \\
\text { (\%) }\end{array}$ & $\begin{array}{l}\text { PPV } \\
(\%)\end{array}$ & $\begin{array}{l}\text { NPV } \\
(\%)\end{array}$ & $\begin{array}{l}\mathrm{AC} \\
(\%)\end{array}$ \\
\hline $\begin{array}{l}\text { FIB } \\
(\mathrm{mg} / \mathrm{dL})\end{array}$ & 0.755 & $\begin{array}{l}0.666- \\
0.830\end{array}$ & $>390$ & 82.35 & 57.81 & 66.12 & 76.61 & 70.08 \\
\hline $\begin{array}{l}\text { D-dimer } \\
(\mu \mathrm{g} / \mathrm{L})\end{array}$ & 0.825 & $\begin{array}{l}0.743- \\
0.889\end{array}$ & $>1230$ & 88.24 & 65.62 & 71.96 & 84.80 & 76.93 \\
\hline $\begin{array}{l}\text { FDP } \\
(\mathrm{mg} / \mathrm{L})\end{array}$ & 0.793 & $\begin{array}{l}0.708 \text { to } \\
0.863\end{array}$ & $>1.81$ & 66.67 & 81.25 & 78.05 & 70.91 & 73.96 \\
\hline $\begin{array}{l}\text { CRP } \\
(\mathrm{mg} / \mathrm{L})\end{array}$ & 0.732 & $\begin{array}{l}0.642 \text { to } \\
0.810\end{array}$ & $>5.41$ & 84.31 & 67.69 & 72.29 & 81.18 & 76.00 \\
\hline $\begin{array}{l}\text { ESR } \\
(\mathrm{mm} / \mathrm{h})\end{array}$ & 0.614 & $\begin{array}{l}0.455 \text { to } \\
0.757\end{array}$ & $>10$ & 32.14 & 93.75 & 83.72 & 58.01 & 62.95 \\
\hline $\mathrm{RF}(\mathrm{IU} / \mathrm{ml})$ & 0.619 & $\begin{array}{l}0.523- \\
0.708\end{array}$ & $>82.3$ & 66.00 & 57.14 & 60.63 & 62.69 & 61.57 \\
\hline $\mathrm{CCP}(\mathrm{U} / \mathrm{ml})$ & 0.543 & $\begin{array}{l}0.445- \\
0.639\end{array}$ & $>73.2$ & 32.65 & 83.33 & 66.20 & 55.30 & 57.99 \\
\hline $\begin{array}{l}\text { AUC, area u } \\
\text { predictive } \\
\text { ESR, erythr }\end{array}$ & cur & $\begin{array}{l}5 \% \mathrm{Cl}, 9 \\
\text { uracy; } \mathrm{F} \\
\text { tation }\end{array}$ & nfide & $\begin{array}{l}\text { val; PPV, } \\
\text { fibrin de } \\
\text { factor, }\end{array}$ & $\begin{array}{l}\text { ive predic } \\
\text { tion prod }\end{array}$ & $\begin{array}{l}\text { valt } \\
\text { CRF }\end{array}$ & $\begin{array}{l}\text { PV, ne } \\
\text { activ }\end{array}$ & $\begin{array}{l}\text { ive } \\
\text { otein; }\end{array}$ \\
\hline
\end{tabular}

\section{Correlation of plasma coagulation-related markers with disease activity and laboratory parameters}

To further evaluate the relationship between plasma coagulation-related markers and disease activity and laboratory parameters, we conducted a correlation analysis between plasma levels of these markers and disease activity index DAS-28 CRP and laboratory parameters including CRP and ESR.

FIB was positively associated with DAS-28 CRP $(r=0.422, P<0.001), C R P(r=0.557, P<0.001)$ and ESR $(r=0.502, P<0.001)$. D-dimer was positively associated with DAS-28 CRP $(r=0.490, P<0.001), \operatorname{CRP}(r=$ $0.647, P<0.001)$ and ESR $(r=0.619, P<0.001)$. FDP was positively associated with DAS-28 CRP $(r=$ $0.491, P<0.001), C P R(r=0.611, P<0.001)$ and ESR $(r=0.568, P<0.001)$. Notably, the correlation between D-dimer and disease activity parameters such as CRP and ESR was the strongest. 


\section{Binary logistic regression analysis of factors independently associated with disease activity in RA patients}

In addition, we performed logistic regression analysis to assess the associated factors with RA disease activity. After univariate regression analysis, D-dimer and FDP were used for further multivariate regression analysis $(P<0.10)$. Results showed that only $D$-dimer is an independent predictor for $R A$ disease activity $(\mathrm{OR}=2.862,95 \% \mathrm{Cl}:(1.851-4.426), \mathrm{P}<0.001)$ (Table 6).

Table 6

Logistic regression analysis of the predictors for the disease activity in RA patients.

\begin{tabular}{|c|c|c|c|c|c|c|}
\hline \multirow[t]{2}{*}{ Predictors } & \multicolumn{3}{|c|}{ Univariate regression analyses } & \multicolumn{3}{|c|}{ Multivariate regression analyses } \\
\hline & $\beta$ & OR $(95 \% \mathrm{Cl})$ & $\begin{array}{l}P \text { - } \\
\text { value }\end{array}$ & $\beta$ & OR $(95 \% \mathrm{Cl})$ & $\begin{array}{l}P \text { - } \\
\text { value }\end{array}$ \\
\hline Gender & 0.282 & $1.326(0.109-16.133)$ & 0.825 & & & \\
\hline Age & -0.414 & $0.661(0.251-1.740)$ & 0.402 & & & \\
\hline $\begin{array}{l}\text { Duration of } \\
\text { RA }\end{array}$ & 0.600 & $1.823(.243-13.673)$ & 0.559 & & & \\
\hline ESR & -1.670 & $0.188(0.018-1.993)$ & 0.165 & & & \\
\hline CRP & -0.185 & $0.831(0.106-6.483)$ & 0.860 & & & \\
\hline RF & 0.367 & $1.443(0.438-4.756)$ & 0.547 & & & \\
\hline $\mathrm{CCP}$ & 0.042 & $1.043(0.474-2.293)$ & 0.917 & & & \\
\hline FIB & 0.457 & $1.580(0.185-13.462)$ & 0.676 & & & \\
\hline D-dimer & 2.931 & $\begin{array}{l}18.752(1.898- \\
185.223)\end{array}$ & 0.012 & 1.052 & $\begin{array}{l}2.862(1.851- \\
4.426)\end{array}$ & .000 \\
\hline FDP & -2.168 & $0.114(0.010-1.359)$ & 0.086 & & & \\
\hline
\end{tabular}

\section{Discussion}

This study showed that RA patients had higher levels of FIB, D-dimer and FDP than healthy individuals. FIB, D-dimer and FDP were significantly elevated in patients with active RA than those in inactive group. Additionally, plasma levels of these coagulation markers were positively related with the RA disease activity score DAS-28 CRP, CRP and ESR. These markers contribute to distinguish between active RA and 
inactive RA. Logistic regression analyses illustrated that high D-dimer indicated increased risk of RA disease activity.

FIB is an important glycoprotein present in human blood plasma and it is involved in many physiological processes such as wound healing, tissue regeneration and regulation of inflammatory responses [25]. Moreover, FIB has been shown an important determinant of inflammatory arthritis through its effects on proinflammatory pathways such as NF-KB signaling [26]. It has been demonstrated that the multiple regions of the FIB molecule could bind to $C D 11 \mathrm{~b} / \mathrm{CD} 18$ integrin receptor expressed on leukocytes of the innate immune system including circulating monocytes, tissue-specific macrophages, and so on [27, 28]. Emerging evidence from in vitro studies and animal models implicates FIB in the pathogenesis of RA. For example, an in vitro study showed that treatment of synovial fibroblasts with FIB was followed by IL-8 secretion and upregulation of ICAM-1 expression, resulting in increased adhesiveness of lymphocytes [26]. Another animal study revealed that mice lacking FIB or missing only the CD11b/CD18 integrin receptor-binding domain and challenged with collagen-induced arthritis had fewer arthritic joints compared with control mice [29]. A recent study showed that circulating levels of FIB are elevated in RA and correlated with markers of inflammation [30]. In this study, the finding of a significant association between plasma levels of FIB and disease activity of RA patients may be a consequence of increased synovialis and articular cartilage injury in RA patients with increased FIB concentration.

FDP and D-dimer are derived from the fibrin clot breakdown by plasmain. As traditional markers of fibrinolysis, FDP and D-dimer have been analyzed for monitoring venous thromboembolism and preoperative coagulation control. Recently there are several studies reporting that FDP and D-dimer levels were elevated in the setting of systemic inflammation and infection [25, 31, 32]. A previous study reported that that the rise and fall of serum D-dimer is more rapid than serum CRP and ESR in patients with periprosthetic joint infection and the test of serum D-dimer might be applied effectively in diagnosing early postoperative infection [33]. Ma et al. demonstrated that plasma levels of $D$-dimer were associated with disease activity of ANCA-associated vasculitis [34]. A prospective study conducted on patients with chronic spontaneous urticaria has reported that patients with autoimmune status had higher levels of plasma D-dimer than those without autoimmunity [35]. Weinberg et al. reported that there were higher levels of D-dimer in the synovium of patients with RA than that in patients with OA and traumatic joint abnormalities [36]. Although previous studies have reported that D-dimer levels were significantly higher in RA patients than in controls, little is known about the relationship between plasma levels of FDP and Ddimer and the disease activity in RA patients. A previous study focusing on the patients with systemic juvenile idiopathic arthritis indicated that D-dimer could more accurately reflect the disease activity and prognosis as compared to clinical features [37]. Consistent with this study, we found that plasma levels of FDP and D-dimer were significantly related to the severity of patients with RA. Moreover, in our study, high level of plasma D-dimer was identified to be an independent predictor for RA disease activity by the regression analysis.

This study has some limitations. Firstly, this study was a single center study and has the relatively low number of patients. Secondly, this study was a retrospective study, which couldn't be used for explicating 
the causality between coagulation related markers and the disease activity of RA. The prospective studies of large-scale and multi-center are required to confirm our findings and to clarify the mechanism underlying the relationship between these markers and RA.

In summary, this study systematically investigated the role of FIB, FDP and D-dimer as biomarkers in determining the disease activity of RA. We found that plasma fibrinogen, D-dimer, and FDP was increased in RA patients and positively correlated with RA disease activity. High D-dimer was revealed as an independent predictor for the disease activity in RA patients. This study indicated that D-dimer may be an effective biomarker for predicting disease activity in RA patients.

\section{Abbreviations}

RA: Rheumatoid arthritis; BMI: body mass index; DAS28-CRP, Disease Activity Score in 28 joints based on C-reactive protein; CRP, C-reactive protein; ESR, erythrocyte sedimentation rate; RF, rheumatoid factor; $C C P$, anti-cyclic citrullinated peptide; Ig G: immunoglobulin G; Ig A: immunoglobulin A; Ig M: immunoglobulin M; WBC, white blood cells; RBC, red blood cells; Hb: hemoglobin; PLT: platelet; FIB: fibrinogen; FDP: fibrin degradation product; ROC: Receiver operating characteristic; AUC, area under curve; $95 \% \mathrm{Cl}, 95 \%$ confidence interval; PPV, positive predictive value; NPV, negative predictive value; AC, accuracy.

\section{Declarations}

\section{Acknowledgements}

We would like to thank Mrs. Junrong Wang for facilitating the data collection.

\section{Authors' contributions}

$L X, Y G, K L, X Y L, W W$ designed the experiment strategy and wrote the manuscript. $M L, L T, Y P Z$, and $Z S L$ assessed patients and collect data. YW, BW, NG, and YYD performed the experiments. TZ, HLL, and JTH conducted statistical analyses and interpreted the data. The authors read and approved the final manuscript.

\section{Funding}

This study was supported by National Natural Science Foundation of China (No. 81802129) and Science and Technology Planning Project of Shaanxi Province of China (No. S2020-YF-YBSF-0344).

\section{Availability of data and materials}


The datasets used and analyzed in the current study are available from the corresponding author upon reasonable request.

\section{Ethics approval and consent to participate}

The study was approved by the Research Committee of Human Investigation of Xi'an Jiaotong University Health Science Center, and written informed consent was obtained from all participants involved in the study.

\section{Consent for publication}

Not applicable.

\section{Competing interests}

The authors declare that they have no competing interests.

\section{Author details}

${ }^{1}$ Department of Clinical Laboratory, The Second Affiliated Hospital of Xi'an Jiaotong University, Xi'an, 710004, China. ${ }^{2}$ Department of Cardiovascular Surgery, The First Affiliated Hospital of Xi'an Jiaotong University, Xi'an, 710061, China. ${ }^{3}$ Department of Rheumatology, The Second Affiliated Hospital of Xi'an Jiaotong University, Xi'an, 710061, China. ${ }^{4}$ Department of Bone and Joint Surgery, The Second Affiliated Hospital of Xi'an Jiaotong University, Xi'an, 710061, China. ${ }^{5}$ Department of Immunology and Pathogenic Biology, Health Science Center, Xi'an Jiaotong University, Xi'an, 710061, China. ${ }^{6}$ Core Research Laboratory, The Second Affiliated Hospital of Xi'an Jiaotong University, Xi'an, China; National Local Joint Engineering Research Centre of Biodiagnostics and Biotherapy, The Second Affiliated Hospital of Xi'an Jiaotong University, Xi'an, China.

\section{References}

1. Mclnnes IB, Schett G. The pathogenesis of rheumatoid arthritis. N Engl J Med. 2011;365(23):220519.

2. Scott DL, Wolfe F, Huizinga TW. Rheumatoid arthritis. Lancet. 2010;376(9746):1094-108.

3. Smolen JS, Aletaha D, Mclnnes IB. Rheumatoid arthritis. Lancet. 2016;388(10055):2023-38.

4. Wakefield RJ, Gibbon WW, Conaghan PG, O'Connor P, McGonagle D, Pease C, Green MJ, Veale DJ, Isaacs JD, Emery P. The value of sonography in the detection of bone erosions in patients with 
rheumatoid arthritis: a comparison with conventional radiography. Arthritis rheumatism. 2000;43(12):2762-70.

5. Burzynski LC, Humphry M, Pyrillou K, Wiggins KA, Chan JNE, Figg N, Kitt LL, Summers C, Tatham KC, Martin PB, et al. The Coagulation and Immune Systems Are Directly Linked through the Activation of Interleukin-1alpha by Thrombin. Immunity. 2019;50(4):1033-42 e1036.

6. Arneth B. Coevolution of the coagulation and immune systems. Inflammation research: official journal of the European Histamine Research Society [et al]. 2019;68(2):117-23.

7. Wang L, Duan J, Bian T, Meng R, Wu L, Zhang Z, Zhang X, Wang C, Ji X. Inflammation is correlated with severity and outcome of cerebral venous thrombosis. J Neuroinflamm. 2018;15(1):329.

8. Levi M, van der Poll T, Schultz M. Infection and inflammation as risk factors for thrombosis and atherosclerosis. Semin Thromb Hemost. 2012;38(5):506-14.

9. Popescu NI, Girton A, Burgett T, Lovelady K, Coggeshall KM. Monocyte procoagulant responses to anthrax peptidoglycan are reinforced by proinflammatory cytokine signaling. Blood advances. 2019;3(16):2436-47.

10. Dela Cadena RA, Majluf-Cruz A, Stadnicki A, Tropea M, Reda D, Agosti JM, Colman RW, Suffredini AF. Recombinant tumor necrosis factor receptor $\mathrm{p} 75$ fusion protein (TNFR:Fc) alters endotoxin-induced activation of the kinin, fibrinolytic, and coagulation systems in normal humans. Thromb Haemost. 1998;80(1):114-8.

11. Senchenkova EY, Komoto S, Russell J, Almeida-Paula LD, Yan LS, Zhang S, Granger DN. Interleukin-6 mediates the platelet abnormalities and thrombogenesis associated with experimental colitis. Am J Pathol. 2013;183(1):173-81.

12. Senchenkova EY, Russell J, Yildirim A, Granger DN, Gavins FNE. Novel Role of T Cells and IL-6 (Interleukin-6) in Angiotensin II-Induced Microvascular Dysfunction. Hypertension. 2019;73(4):82938.

13. Zelaya $\mathrm{H}$, Rothmeier AS, Ruf W. Tissue factor at the crossroad of coagulation and cell signaling. Journal of thrombosis haemostasis: JTH. 2018;16(10):1941-52.

14. Marzano AV, Tedeschi A, Polloni I, Crosti C, Cugno M. Interactions between inflammation and coagulation in autoimmune and immune-mediated skin diseases. Curr Vasc Pharmacol. 2012;10(5):647-52.

15. So AK, Varisco PA, Kemkes-Matthes B, Herkenne-Morard C, Chobaz-Peclat V, Gerster JC, Busso N. Arthritis is linked to local and systemic activation of coagulation and fibrinolysis pathways. Journal of thrombosis haemostasis: JTH. 2003;1(12):2510-5.

16. Wendling D, Racadot E. Serum tissue factor levels correlate with inflammation in ankylosing spondylitis. Joint bone spine. 2006;73(4):403-5.

17. Frijns R, Fijnheer R, Schiel A, Donders R, Sixma J, Derksen R. Persistent increase in plasma thrombomodulin in patients with a history of lupus nephritis: endothelial cell activation markers. $J$ Rhuematol. 2001;28(3):514-9. 
18. Chang X, Yamada R, Yamamoto K. Inhibition of antithrombin by hyaluronic acid may be involved in the pathogenesis of rheumatoid arthritis. Arthritis research therapy. 2005;7(2):R268-73.

19. van den Oever IA, Sattar N, Nurmohamed MT. Thromboembolic and cardiovascular risk in rheumatoid arthritis: role of the haemostatic system. Ann Rheum Dis. 2014;73(6):954-7.

20. Robson SC, Shephard EG, Kirsch RE. Fibrin degradation product D-dimer induces the synthesis and release of biologically active IL-1 beta, IL- 6 and plasminogen activator inhibitors from monocytes in vitro. Br J Haematol. 1994;86(2):322-6.

21. Mandl J, Csala M, Lerant I, Banhegyi G, Biro J, Machovich R, Falus A. Enhancement of interleukin-6 production by fibrinogen degradation product $D$ in human peripheral monocytes and perfused murine liver. Scand J Immunol. 1995;42(1):175-8.

22. Aletaha D, Neogi T, Silman A, Funovits J, Felson D, Bingham C. 2010 rheumatoid arthritis classification criteria. An American College of Rheumatology/European League Against Rheumatism Collaborative Initiative. Ann Rheum Dis. 2010;63:573-86.

23. Inoue $E$, Yamanaka $H$, Hara $M$, Tomatsu T, Kamatani N. Comparison of Disease Activity Score (DAS) 28-erythrocyte sedimentation rate and DAS28-C-reactive protein threshold values. Ann Rheum Dis. 2007;66:407-9.

24. Nakano S, Morimoto S, Suzuki S, Tsushima H, Yamanaka K, Sekigawa I, Takasaki Y. Immunoregulatory role of IL-35 in T cells of patients with rheumatoid arthritis. Rheumatology (Oxford, England) 2015, 54.

25. Davalos D, Akassoglou K. Fibrinogen as a key regulator of inflammation in disease. Semin Immunopathol. 2012;34(1):43-62.

26. Liu X, Piela-Smith TH. Fibrin(ogen)-induced expression of ICAM-1 and chemokines in human synovial fibroblasts. Journal of immunology. 2000;165(9):5255-61.

27. Ugarova TP, Yakubenko VP. Recognition of fibrinogen by leukocyte integrins. Ann N Y Acad Sci. 2001;936:368-85.

28. Lishko VK, Podolnikova NP, Yakubenko VP, Yakovlev S, Medved L, Yadav SP, Ugarova TP: Multiple binding sites in fibrinogen for integrin alphaMbeta2 (Mac-1). The Journal of biological chemistry 2004, 279(43):44897-44906.

29. Flick MJ, LaJeunesse CM, Talmage KE, Witte DP, Palumbo JS, Pinkerton MD, Thornton S, Degen JL. Fibrin(ogen) exacerbates inflammatory joint disease through a mechanism linked to the integrin alphaMbeta2 binding motif. J Clin Investig. 2007;117(11):3224-35.

30. Rooney T, Scherzer R, Shigenaga JK, Graf J, Imboden JB, Grunfeld C. Levels of plasma fibrinogen are elevated in well-controlled rheumatoid arthritis. Rheumatology. 2011;50(8):1458-65.

31. Ribera T, Monreal L, Armengou L, Rios J, Prades M. Synovial fluid D-dimer concentration in foals with septic joint disease. J Vet Intern Med. 2011;25(5):1113-7.

32. Gobel K, Eichler S, Wiendl H, Chavakis T, Kleinschnitz C, Meuth SG. The Coagulation Factors Fibrinogen, Thrombin, and Factor XII in Inflammatory Disorders-A Systematic Review. Frontiers in immunology. 2018;9:1731. 
33. Xiong L, Li S, Dai M. Comparison of D-dimer with CRP and ESR for diagnosis of periprosthetic joint infection. J Orthop Surg Res. 2019;14(1):240.

34. Ma TT, Huang YM, Wang C, Zhao MH, Chen M. Coagulation and fibrinolysis index profile in patients with ANCA-associated vasculitis. PloS one. 2014;9(5):e97843.

35. de Montjoye L, Darrigade AS, Gimenez-Arnau A, Herman A, Dumoutier L, Baeck M: Correlations between disease activity, autoimmunity and biological parameters in patients with chronic spontaneous urticaria. European annals of allergy and clinical immunology 2020.

36. Weinberg JB, Pippen AM, Greenberg CS. Extravascular fibrin formation and dissolution in synovial tissue of patients with osteoarthritis and rheumatoid arthritis. Arthritis rheumatism. 1991;34(8):9961005.

37. Bloom BJ, Alario AJ, Miller LC. Persistent elevation of fibrin D-dimer predicts longterm outcome in systemic juvenile idiopathic arthritis. J Rhuematol. 2009;36(2):422-6.

\section{Figures}

\section{A}

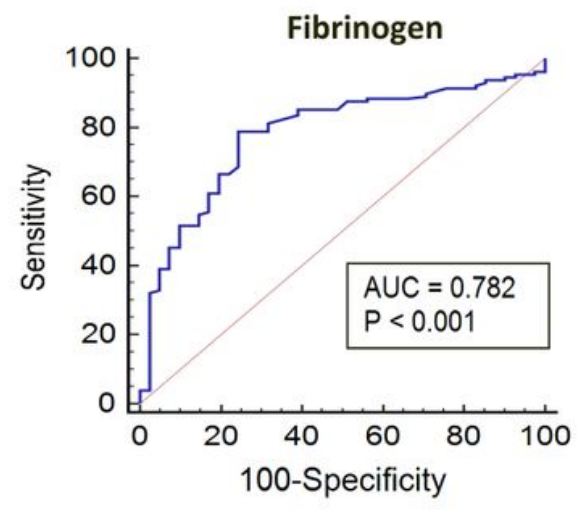

B

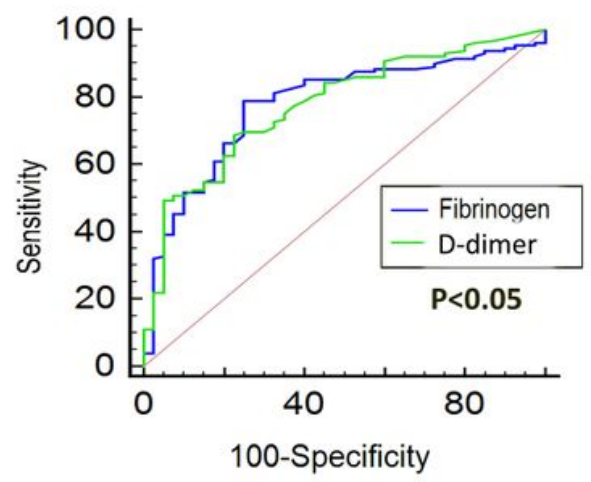

D-dimer
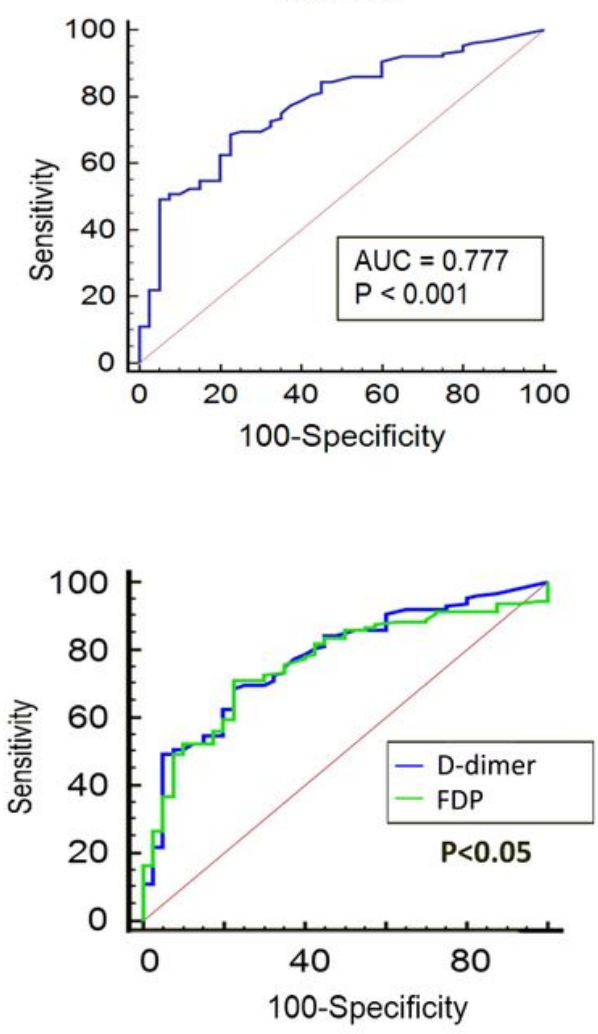

FDP
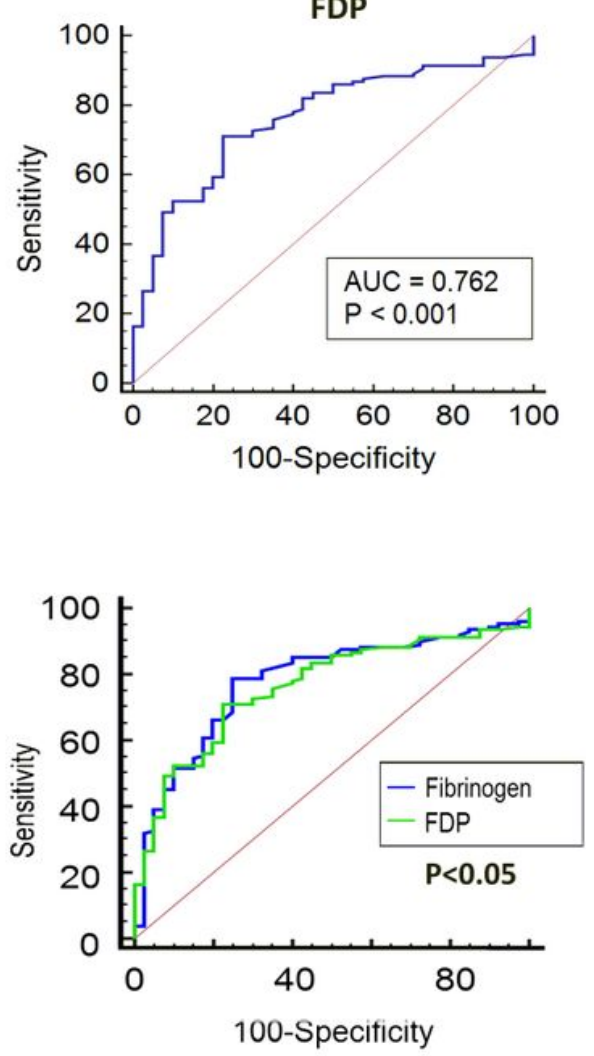

\section{Figure 1}

Performance of plasma fibrinogen, D-dimer, and FDP in discriminating RA patients from healthy controls. (A) The ROC curves of the three markers in differentiating RA patients from healthy controls. (B) 
Comparison of ROC curves among the three markers. ROC, receiver operating characteristic curve; FDP, fibrin degradation product.

A
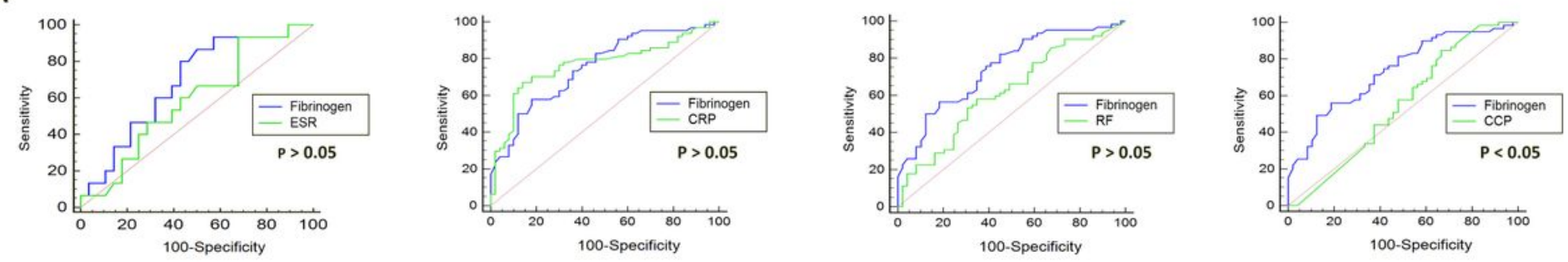

B
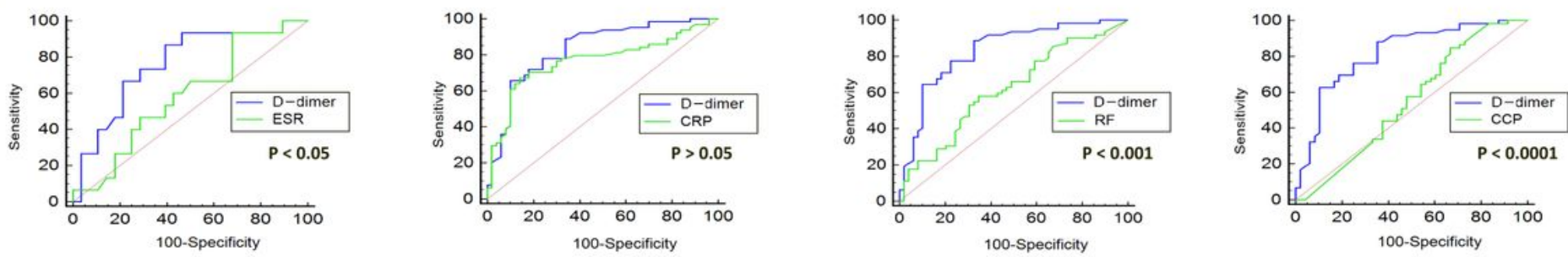

C
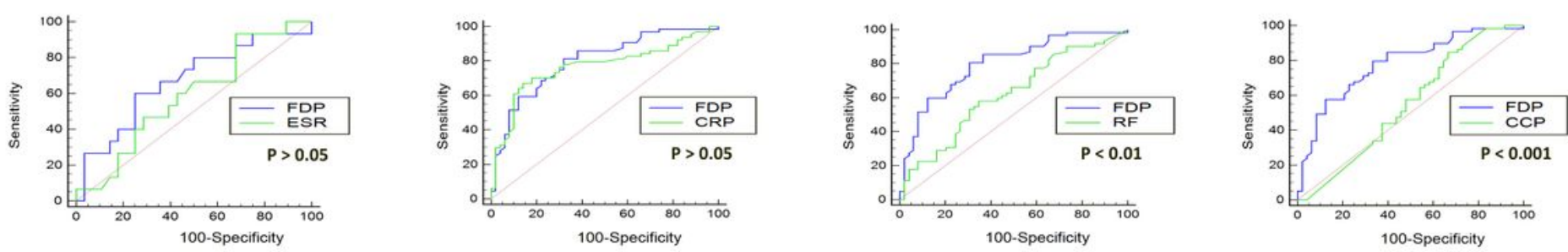

Figure 2

Performance of plasma fibrinogen, D-dimer, and FDP in discriminating active RA patients from inactive RA patients. Comparison of ROC curves between fibrinogen (A), D-dimer (B) or FDP (C) and other parameters including ESR, CRP, RF and CCP in differentiating RA patients from healthy controls. ROC, receiver operating characteristic curve; FDP, fibrin degradation product; ESR, erythrocyte sedimentation rate; CRP, C-reactive protein; RF, rheumatoid factor; $C C P$, anti-cyclic citrullinated peptide antibody. 